\title{
SOBRE FORMA Y SUSTANCIA: UNA EVALUACIÓN DE LA DEMOCRACIA ELECTORAL EN COLOMBIA*
}

\author{
On Form and Substance: An Assessment of Electoral Democracy in \\ Colombia
}

\section{FELIPE BOTERO}

Universidad de los Andes, Bogotá

\section{GARY W. HOSKIN}

Universidad de los Andes, Bogotá

\section{MÓNICA PACHÓN}

Universidad de los Andes, Bogotá

\begin{abstract}
RESUMEN
Este artículo hace un balance del estado de la democracia en Colombia resaltando la fuerte tensión entre la forma y la sustancia. Aunque existen instituciones que generan la apariencia de una democracia consolidada, éstas conviven en un entorno que socava su legitimidad. Sostenemos que las principales amenazas para la democracia en Colombia provienen de dos fuentes. Hay amenazas provenientes de factores "externos" relacionados al accionar de actores armados ilegales tales como paramilitares, guerrilleros y narcotraficantes. Igualmente, hay amenazas provenientes de factores "internos", en particular por los desbalances entre las ramas del poder resultantes de la continuación del presidente Uribe en su cargo. Nuestra evaluación se concentra fundamentalmente en las instituciones políticas y las percepciones que los ciudadanos tienen de ellas.
\end{abstract}

Palabras clave: Democracia, amenazas, consolidación democrática.

\begin{abstract}
This article assesses the state of democracy in Colombia stressing the strong tension between form and substance. Although there are institutions that create the appearance of a consolidated democracy, these are immersed in a milieu that undermines their legitimacy. We maintain that the main threats to Colombian democracy come from two sources. There are "external" threats related to the actions of diverse illegal armed actors such as paramilitaries, guerrillas, and drug lords. Additionally, there are "internal" factors, specially those created by the lack of checks and balances that result from president Uribe's tenure. Our assessment focuses on political institutions and citizens perceptions of them.
\end{abstract}

Key words: Democracy, threats, democratic consolidation.

* Versiones preliminares de este trabajo se presentaron a la Red de Investigación sobre la Democracia Andina en Ottawa, Canadá, en octubre de 2008, en una reunión con diversos miembros de la sociedad civil y ONG, evento patrocinado por el proyecto Fortalecimiento Democrático del PNUD-IDEA en marzo de 2009, en Bogotá, y en el Congreso de la Asociación de Estudios Latinoamericanos (LASA) en Rio de Janeiro, Brasil, en junio de 2009. Agradecemos a los participantes en estos eventos por sus valiosos comentarios y los comentarios de dos evaluadores anónimos de la RCP. Igualmente, agradecemos la asistencia de investigación prestada por Daniel González y Laura Otálora y al PNUD-IDEA por el gentil apoyo que han prestado a nuestro proyecto. 


\section{INTRODUCCIÓN}

El funcionamiento de la democracia en Colombia ofrece lecciones importantes para las democracias de la región. Principalmente, es preciso resaltar que la existencia de instituciones formales que garanticen los derechos de los ciudadanos y protejan el estado de derecho puede no ser suficiente para lograr una democracia legítima, equitativa y justa. Es así como los avances democráticos que logró el país en materia formal, tras una larga trayectoria de democracia electoral y la aprobación en 1991 de una Constitución progresiva y garantista, se ven desmejorados por una serie de fenómenos que, no siendo completamente ajenos a la realidad de países vecinos, han tomado ventaja en Colombia: clientelismo, tráfico de drogas, conflicto armado interno y la erosión de los pesos y contrapesos característicos de las democracias maduras. En este artículo hacemos un balance del estado de la democracia en Colombia resaltando la fuerte tensión entre la forma y la sustancia. Existen instituciones que generan la apariencia de una democracia consolidada, pero éstas conviven en un entorno que socava la legitimidad misma de esas instituciones y limita su capacidad de producir los resultados esperables de la democracia plena.

Las principales amenazas para la democracia en Colombia provienen de dos fuentes, a nuestro juicio. En primer lugar, la democracia está amenazada por una serie de factores "externos" relacionados con la situación de orden público y el accionar de diferentes actores armados ilegales tales como paramilitares, guerrilleros y narcotraficantes. Así, la crisis de la parapolítica ha socavado la legitimidad de las instituciones fundamentales de la representación democrática: los partidos políticos y el Congreso. El Congreso colombiano se ha visto diezmado, con 73 miembros del Congreso bajo investigación y 30 condenados y encarcelados por sus vínculos con los grupos paramilitares, para el momento en que se escribe este trabajo. La oficina del Fiscal General ha entregado información a la Corte Suprema que facilitará la investigación de cinco miembros, pues expone sus vínculos con grupos de la guerrilla izquierdista. Estos escenarios han generado una valoración pésima que afecta el respaldo que la ciudadanía podría otorgar tanto al Congreso como a los partidos políticos colombianos, y, de igual manera, ha socavado la habilidad del Congreso para ejecutar sus tareas legislativas, con consecuencias desastrosas para la amplitud y calidad de la representación política en la democracia de Colombia.

A pesar de los logros recientes de la política de "seguridad democrática" del gobierno, relacionados con las guerrillas izquierdistas, es poco probable que el movimiento guerrillero desaparezca en el futuro inmediato, lo cual dejará intacto el problema del intercambio humanitario existente entre las víctimas del secuestro y guerrilleros encarcelados, junto con la probabilidad de que la violencia continúe, especialmente en la parte sur del país. Además, nuevos y reconstituidos grupos paramilitares derechistas han emergido en varias partes del país, lo que complica aún más los esfuerzos de pacificación del gobierno. Junto con los ataques de grupos ilegales -tanto de la izquierda como de la derecha- a las instituciones democráticas colombianas, el impacto del narcotráfico sigue siendo enorme. A pesar de la extradición reciente de 14 prominentes líderes paramilitares profundamente involucrados en el tráfico de drogas, y la confiscación continua de 
drogas ilícitas y la destrucción de laboratorios para el procesamiento de la misma, la influencia política y la penetración de las instituciones democráticas del país por los narcotraficantes no desaparecerán. La violencia y la anarquía que provienen de los grupos paramilitares y guerrilleros, así como del narcotráfico, permanecerán como un reto significativo a la viabilidad de la democracia colombiana. Esto es particularmente visible a nivel subnacional de la política con elecciones locales y regionales que ocurren bajo condiciones que están lejos de ser realmente "poliárquicas".

En segundo lugar, la democracia colombiana se ve también amenazada por factores "internos", en particular por los desbalances entre las ramas del poder que han resultado de la continuación del presidente Uribe en su cargo. La Constitución de 1991 otorgó poder a las tres ramas del gobierno, con controles y balances entre ellas. No obstante, este delicado balance fue socavado como consecuencia de un cambio constitucional introducido en 2005 que le permitió al presidente Uribe buscar un segundo mandato, mientras mantenía un esfuerzo continuo para asegurar firmas para un referendo que le permitiera buscar otros cuatro años adicionales en el poder. En consecuencia, el balance de poder ha cambiado significativamente en favor de la presidencia, permitiendo al Presidente adquirir más influencia sobre la rama judicial a través del nombramiento de jueces durante dos, o quizás tres periodos, lo cual va aunado con un aumento similar de poder sobre las decisiones del Banco de la República. Adicionalmente, el presidente Uribe no ha aceptado en buenos términos los fallos de la Corte Constitucional o la Corte Suprema que no han favorecido iniciativas gubernamentales. Además, no ha repudiado el movimiento que le permitiría buscar un tercer mandato presidencial, y es probable que este asunto genere una polarización significativa entre los actores políticos, aunque obviamente no con el mismo impacto en el público votante, que sin duda reelegiría al presidente Uribe si se le permitiera.

Igualmente, otra fuente de preocupación por la salud de la democracia colombiana tiene que ver con la relación existente entre el gobierno de Uribe y la oposición, relación que frecuentemente es tensa, en especial con el Polo Democrático, y en una escala menor, con el Partido Liberal. El gobierno tiende a no ser particularmente tolerante respecto a las críticas que emanan de los grupos y partidos de la oposición. En efecto, el gobierno frecuentemente desacredita y silencia a la oposición en un intento por invisibilizar las críticas frente a ciertos temas. Esto ha sido en especial en lo que respecta al escándalo de las relaciones con el paramilitarismo.

Para resumir, los retos que enfrenta la democracia colombiana son formidables, y los prospectos para ahondar aún más la desinstitucionalización no son insignificantes. Los rasgos carismáticos, y frecuentemente autoritarios, del liderazgo del presidente Uribe podrían implicar repercusiones serias para el sistema político. Entre tanto, el éxito gubernamental consistente en afianzar la seguridad del país mediante la pacificación de los grupos de izquierda y de derecha podría ser un requisito para la estabilidad democrática. De igual manera, el énfasis sobre la profundización capitalista al parecer no ha impactado notablemente sobre políticas que combatan la inequidad social y económica y la incidencia de la pobreza en el país, factores que no conducen a la viabilidad económica. 
Nuestra evaluación se concentra fundamentalmente en las instituciones políticas y las percepciones que los ciudadanos tienen de ellas. El artículo está diseñado de la siguiente manera: la sección 2 está referida fundamentalmente al componente electoral y pretende indicar hasta qué punto las elecciones son libres, limpias y competitivas. En esta sección argumentamos que un análisis somero revela que los aspectos formales de la democracia están presentes en Colombia y han sido respetados durante el último medio siglo. Sin embargo, una inspección más cercana sobre la forma en que la democracia funciona en Colombia revela rasgos y prácticas preocupantes que son nefastos para la calidad de la democracia. La democracia colombiana ha padecido de algunas de las patologías comunes de las democracias latinoamericanas, como el clientelismo (Leal y Dávila, 1990; Fonseca, 2008) y los problemas de representación urbano-rural (malapportionment) (Archer y Shugart, 1997; Samuels y Snyder, 2001). Aunque sean preocupantes, son problemas menores que no la amenazan. Aun en sus extremos más vulgares -el intercambio de votos-, el clientelismo es una forma de relación que deja un mínimo de volición al ciudadano: precisamente la decisión de vender o no su voto. Sugerimos que la amenaza principal a la democracia electoral en Colombia viene de fuentes externas, por medio de diferentes actores ilegales.

La sección 3 está enfocada en la rama legislativa, y busca aclarar la relación existente entre el Congreso y la rama ejecutiva del gobierno. Allí nos preguntamos qué tan estrechamente el comportamiento legislativo colombiano refleja las pautas características de un Congreso democrático. Comenzamos con una discusión sobre el sistema político de partidos para describir los desarrollos más recientes durante las dos administraciones de Uribe. También describimos las instituciones que regulan las relaciones legislativas y ejecutivas, y su situación actual. En la parte final de la sección se analiza el impacto de la amenaza "interna" a la democracia proveniente de la concentración de poder en las manos del Ejecutivo y los problemas asociados con las relaciones entre las diferentes ramas del poder.

La sección 4 presenta unos comentarios a manera de conclusión.

\section{FORMA VS. SUSTANCIA: LA DEMOCRACIA ELECTORAL}

Antes de pasar a una evaluación más detallada de la democracia electoral en el país, es conveniente mirar algunos índices de democracia que evalúan la actuación de la democracia colombiana. Aquí consideramos tres evaluaciones independientes bien acreditadas y conocidas: el Índice de Democracia Electoral (IDE) del PNUD, el Índice de Democracia de la Unidad de Inteligencia de la revista The Economist y la encuesta Libertad en el Mundo de Freedom House.

El Índice de Democracia Electoral (IDE) del PNUD se enfoca solamente sobre los países de América Latina. En promedio, durante el período de 1990-2002, Colombia recibe una nota de 0,57 en una escala de 0-1, lo cual implica el vergonzoso último puesto entre 18 países. Esta nota es bastante inferior al promedio de la región, que es igual a 0,89. De los componentes de este índice, Colombia recibe particularmente bajas notas en la transparencia y la libertad de las elecciones. Esto implica la existencia de "irregularidades 
significantes en el proceso de votación" y "restricciones [...] que afectan la habilidad de los candidatos potenciales para lanzarse a cargos públicos y/o la formación de partidos políticos" (PNUD, 2004: 25-26). La evaluación del PNUD destaca correctamente las limitaciones que muchos colombianos enfrentan para ejercer su derecho al voto y otros derechos democráticos básicos. Como se explica más adelante, dichas limitaciones son el resultado de la influencia de los actores ilegales en todo el país. Las guerrillas, los paramilitares y los narcotraficantes interfieren -de maneras diferentes-con el desarrollo normal de los procesos democráticos para hacer cumplir sus agendas (Duncan, 2007; García Sánchez, 2006).

A su vez, el Índice de Democracia de la Unidad de Inteligencia de la revista The Economist mide más de 60 variables en cinco categorías (proceso y pluralismo electoral, libertades civiles, el funcionamiento del gobierno, la participación política y la cultura política) para evaluar la sustancia y la calidad de las democracias del mundo. En su escala, Colombia está ubicada en el puesto 60 entre 167 países (octavo puesto entre 19 países latinoamericanos). En una escala de 10 puntos, Colombia obtiene 6,54, que es un punto entero más que el promedio mundial (promedio, 5,55; desviación estándar, 2.225). La nota general sitúa a Colombia en una categoría que la revista The Economist llama "democracias defectuosas". Los defectos principales incluyen el funcionamiento del gobierno $(5,38)$, la participación política $(5)$ y la cultura política $(4,38)$. Colombia recibe buenas notas en las otras dos dimensiones: el proceso electoral $(9,17)$ y las libertades civiles $(8,82)$. Este resumen refleja justamente el funcionamiento de la democracia colombiana, de tal manera que las formas están presentes, pero la sustancia y la calidad se encuentran excluidas.

Finalmente, Colombia está clasificada como "parcialmente libre" en el reporte Libertad en el Mundo, la encuesta de Freedom House de 2008. Es un estatus que comparte con tres de los 18 países latinoamericanos (Nicaragua, Paraguay y Venezuela).

Aunque estas evaluaciones no necesariamente están de acuerdo sobre cómo la democracia de Colombia se compara con otras de la región -cambia desde el último puesto al tercio más alto y al tercio más bajo-, todas señalan el hecho de que la democracia colombiana tiene problemas. Las formas están presentes, la sustancia es defectuosa.

Para proseguir con el análisis, discutimos los rasgos formales de la democracia colombiana que apuntan a evaluar la transparencia, la equidad y la libertad de las elecciones del país. Aquí tratamos principalmente los defectos tradicionales, como el clientelismo y las amenazas externas que provienen de los actores ilegales.

\section{a. ¿Son las elecciones libres y transparentes?}

\section{1. ¿Se respeta el derecho al voto?}

Colombia tiene una tradición democrática larga en la cual las elecciones se han llevado a cabo regularmente. Sin embargo, sólo tardíamente en el siglo XX la competitividad se ha convertido en un rasgo distintivo de las elecciones. Los partidos tradicionales -el Conservador y el Liberal- tienen una larga tradición de exclusión mutua del poder. 
Desde 1886 hasta 1930 gobernaron los conservadores, y desde 1930 hasta 1946 fueron los liberales quienes excluyeron a los conservadores. Esta dinámica de exclusión demostró ser muy polarizante, hasta tal punto que el país estuvo al borde de una guerra civil en la década de 1950. Este período -la Violencia- resultó ser muy sangriento, con miles de asesinatos políticos. Un régimen militar breve puso fin al conflicto y hasta permitió a conservadores y a liberales cooperar en la expulsión del general Rojas, que pretendía quedarse en el poder indefinidamente. El resultante acuerdo del Frente Nacional requirió constitucionalmente que los conservadores y los liberales compartieran el poder en todas las ramas del gobierno. Este arreglo implicó que los dos partidos alternaran la presidencia y dividieran el Congreso puntualmente por la mitad. A partir de ese acuerdo, por 16 años ningún otro partido tuvo oportunidad de ser elegido en posiciones nacionales o locales. Una vez que el acuerdo llegó a su fin, la competencia electoral fue restablecida, pero ambos partidos gozaron de una ventaja formidable sobre cualquier otro partido.

Sin embargo, a pesar de sus limitaciones, las elecciones son acontecimientos regulares, y parece que los colombianos las valoran. Los niveles de participación electoral han permanecido alrededor del $45 \%$ durante la última década, que es comparable a democracias bien establecidas y a la mayoría de las demás democracias latinoamericanas. Son niveles de participación bastante buenos, si se tiene en cuenta que la votación no es obligatoria. Por otro lado, los ciudadanos parecen tener grados aceptables de confianza en las instituciones electorales, como se puede ver en la figura $1 .{ }^{1}$ Este gráfico compara las variaciones en los niveles de confianza que los ciudadanos han demostrado en tres instituciones electorales a lo largo del tiempo. No hay mayor cambio en la opinión que los colombianos tienen de estas instituciones entre 2004 y 2007. No obstante, se debería anotar que la confianza fue más alta en 2006, año en que se llevaron a cabo las elecciones nacionales. Es un signo positivo que indica que la confianza es levemente más intensa cuando importa más. La primera institución representada en la figura son las elecciones mismas, que gozan de grados de confianza sobre $50 \%$; el promedio por período es aproximadamente del 53\%. Cuando se preguntó acerca de una institución específica, como el Consejo Nacional Electoral -el tribunal encargado de la supervisión de los procesos electorales-, los niveles de confianza bajaron hasta un poco menos del $50 \%$ (el promedio es aproximadamente $48 \%$ ). No es sorprendente que la confianza en los partidos políticos no sea tan sólida, dado que permanece alrededor del 37\%, que no es poco común respecto de partidos políticos de otras partes. Una interpretación optimista de esta cifra sugiere que los colombianos son capaces de diferenciar entre la confianza en agentes específicos (partidos, Consejo Nacional Electoral) y la confianza en los procedimientos (elecciones), algo parecido a lo que la literatura considera como distinción entre patrones concretos y difusos de apoyo a la democracia (Norris, 1999). Esto quiere decir que los ciudadanos separan los partidos y las instituciones, de los cuales no tienen opiniones favorables, de las elecciones, que valoran como proceso.

1 Los datos sobre las percepciones de los ciudadanos colombianos se toman del Latin America Public Opinion Project (LAPOP; en castellano, Proyecto de Opinión Pública de América Latina), que se lleva a cabo anualmente. Más información en http:/ / www.lapopsurveys.org. 
Esto puede sugerir que mientras no estén cómodos con los resultados -es decir, los partidos que ganan-, pueden esperar que una elección futura producirá resultados más satisfactorios.

Figura 1: Confianza en instituciones electorales

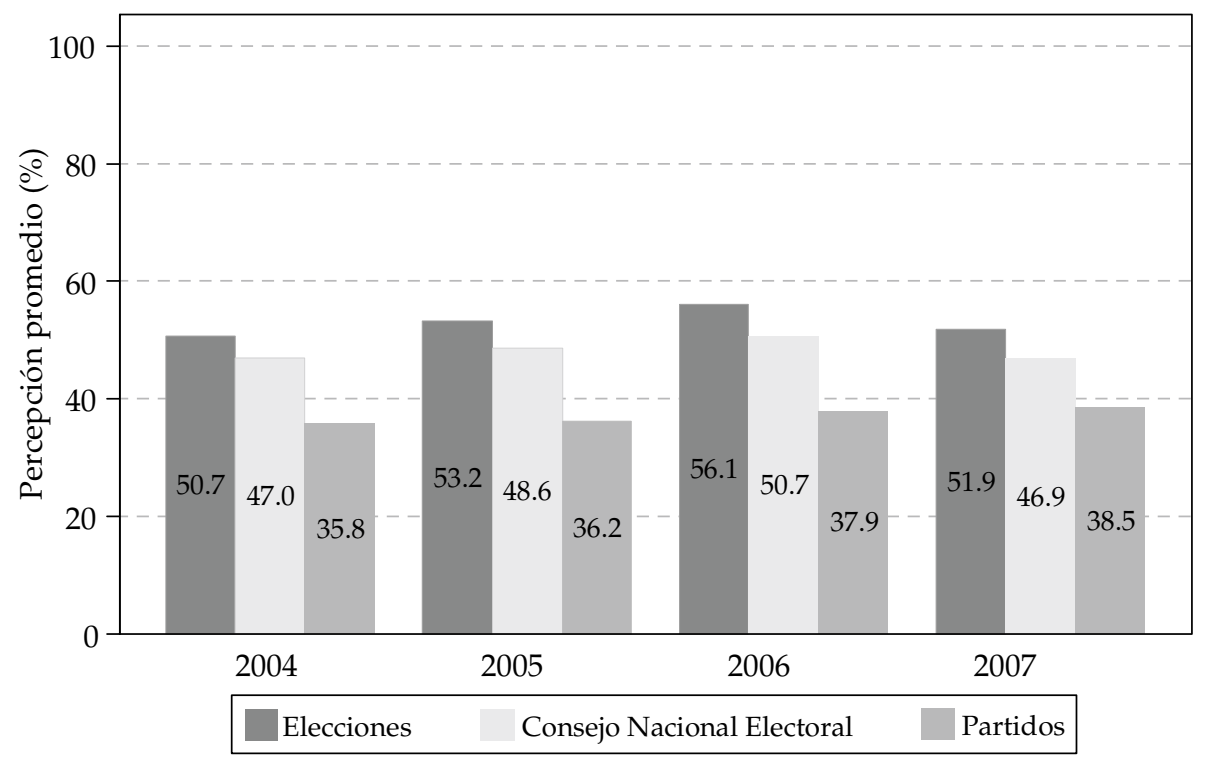

Fuente: LAPOP, Colombia, 2004-2007.

Esta figura muestra los cambios en el tiempo de la percepción de confianza de los colombianos en las elecciones y las instituciones electorales. La cifra revela que mientras casi el $50 \%$ de los colombianos confía en las elecciones mismas y en el Consejo Nacional Electoral, los niveles de confianza caen cuando se trata de los partidos politicos.

Por tanto, podemos afirmar que el derecho al voto se mantiene y es ejercido por los nacionales colombianos. No podemos, sin embargo, afirmar tan fácilmente que éste sea un derecho debidamente respetado. Existe un número de prácticas que afectan el derecho del pueblo a votar libremente. Como se mencionó, los grupos ilegales ejercen diversas presiones sobre los ciudadanos, que directa e indirectamente afectan la manera como se vota. Las acciones de los actores ilegales influyen en la oferta y la demanda de los mercados políticos colombianos, lo que forzosamente impacta el derecho al voto. Los actores ilegales afectan la oferta de los mercados políticos al amenazar a los candidatos con el sabotaje de las elecciones. Ésta es una táctica usada frecuentemente por las guerrillas, los paramilitares y los narcotraficantes en una escala nacional y local, enfocada a individuos o clases enteras de individuos. El ejemplo más truculento quizá sea la exterminación sistemática de los miembros de la Unión Patriótica (UP), un partido 
vinculado con las FARC y creado como resultado de las negociaciones de paz que se llevaron a cabo durante la administración Betancur, a mediados de los años ochenta. En pocos años, entre 2.000 y 5.000 miembros de ese partido -las cifras dependen de quién haga las cuentas- fueron asesinados. Esta práctica se sigue usando en Colombia, e infortunadamente el país continúa siendo el primero en el mundo en términos de asesinatos de líderes sindicales. ${ }^{2}$ No sorprende que la mayoría de estos crímenes no estén resueltos. ${ }^{3}$

De igual manera, líderes nacionales han sido asesinados, incluyendo cuatro candidatos presidenciales: Jaime Pardo en 1987 y Bernardo Jaramillo en 1990, ambos miembros de la Unión Patriótica; Carlos Pizarro del M-19 en 1990 y Luis Carlos Galán del Partido Liberal en 1989. Pero las víctimas más comunes de este tipo de intimidación son los políticos locales que se lanzan como alcaldes o se postulan para cargos de las administraciones municipales o departamentales. Éstos son los políticos que viven en áreas del país donde los actores ilegales son más generalizados. Existen diferentes estrategias a través de las cuales los actores ilegales afectan el proceso electoral (Arjona, 2008; García, 2006; Losada, 2001). Los grupos ilegales pueden estar interesados en determinar los resultados de las elecciones para favorecer candidatos cómplices con el objeto de usurpar el poder con candidatos que tengan vínculos estrechos con el grupo ilegal, estrategia favorecida por los paramilitares. Esta situación se presenta típicamente en alianza o complicidad con los poderes locales en los municipios, y el grado de éxito depende principalmente del nivel de control local que el grupo ilegal pueda tener en una región en particular. Una segunda estrategia, normalmente asociada con la actividad guerrillera, involucra el deseo de los actores ilegales de bloquear las elecciones de manera general. Para hacerlo, los grupos armados amenazan a todos los candidatos e intimidan a los ciudadanos para que se abstengan de votar.

Por el lado de la demanda, los ciudadanos se encuentran presionados por los actores ilegales para votar de una manera determinada, aunque éste es el caso principalmente de las áreas rurales donde las guerrillas o los paramilitares operan. En dichas áreas, los actores ilegales informan a los residentes de un pueblo dado que deben votar por un candidato en particular o que deben abstenerse de votar el día de la elección. Aquellos que retan estas órdenes pueden llegar a ser blancos políticos -lo cual es realmente un eufemismo para decir que las probabilidades de ser asesinados son sumamente altas. Esta práctica ha sido ampliamente documentada (Duncan, 2007; Romero, 2007). Alguna evidencia aparece también en las encuestas de opinión pública, como las conducidas por LAPOP. Como se puede ver en la figura $2 \mathrm{a}$, algunos colombianos reportan haber

2 Según la Confederación Sindical Internacional, durante 2006 hubo 144 asesinatos de miembros de sindicatos en todo el mundo, de los que 78 (55\%) fueron liquidados en Colombia. Este país solo dobla la cantidad de asesinatos de líderes sindicales en Asia y el Pacífico y más que triplica los de África. Las cosas cambiaron poco durante 2007: de 91 sindicalistas que fueron asesinados en el mundo, 39 (42\%) murieron en Colombia. Véase http:/ / www.ituc-csi.org.

3 Esta trayectoria ignominiosa de matar a sindicalistas fue un obstáculo en la negociación de un acuerdo de comercio entre los EE.UU. y Colombia y fue discutida en el Congreso estadounidense. Véase http://www. nytimes.com/2008/04/14/world/americas/14colombia.html?_r=1\&oref=slogin 


\section{Figura 2}

a) Individuos presionados a votar por alguien en particular

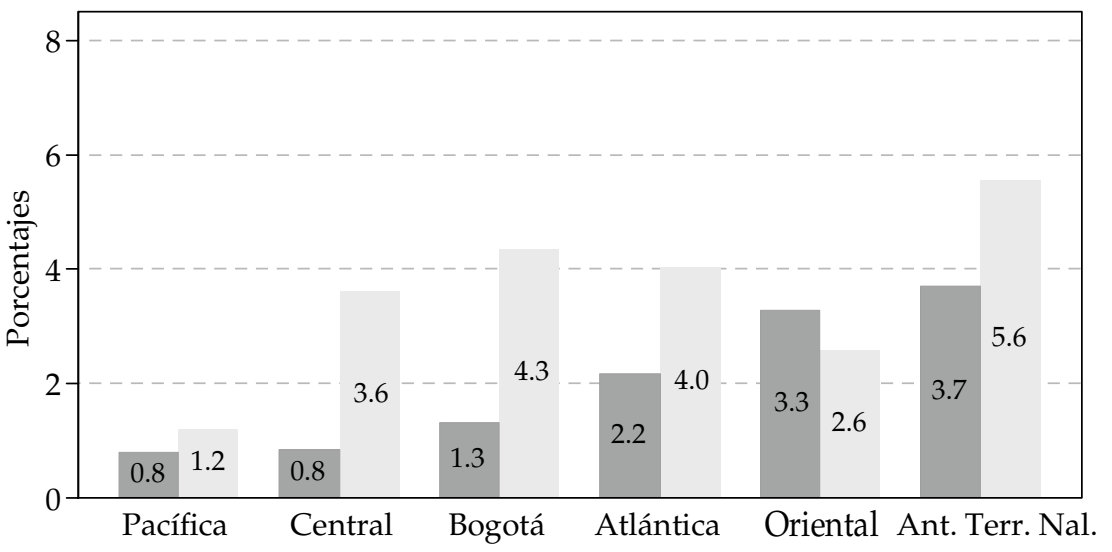

Fue coercionado para votar por alguien

Amigos/parientes fueron coercionados para votar por alguien

Fuente: LAPOP, Colombia, 2007.

b) Individuos presionados a abstenerse de votar

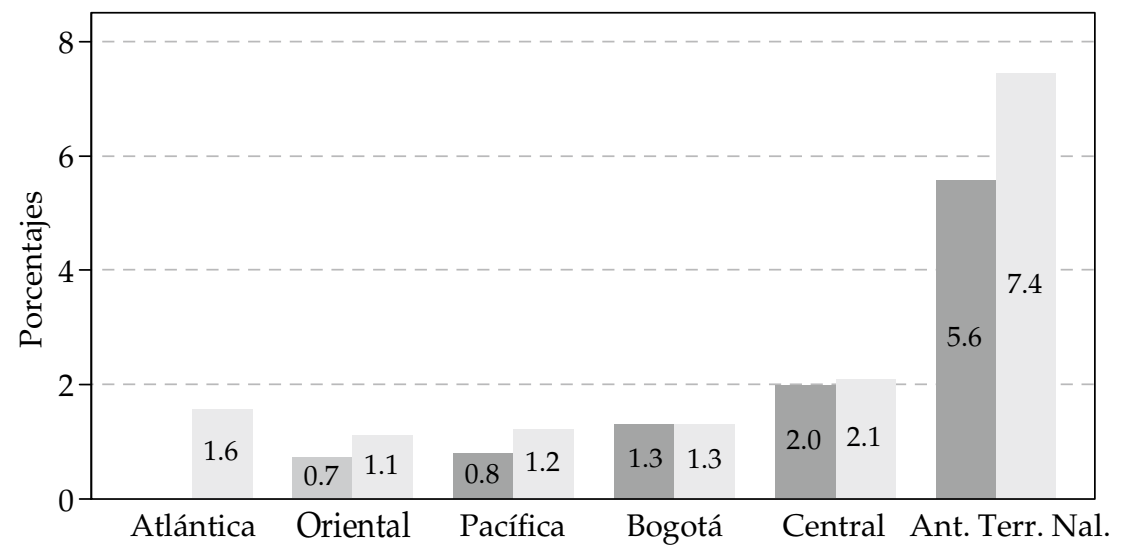

Fue coercionado para no votar

Amigos/parientes fueron coercionados para no votar

Fuente: LAPOP, Colombia, 2007.

Estas figuras muestran hasta qué punto los colombianos estaban sujetos a presiones que limitaron su derecho a votar libremente. El panel superior (a) muestra el porcentaje de encuestados que fueron objeto de amenazas por votar por un candidato en particular, una estrategia comúnmente asociada con tácticas paramilitares. Del mismo modo, el panel inferior (b) muestra los porcentajes de quienes fueron objeto de amenazas para permanecer lejos de las urnas, estrategia más comúnmente utilizada por los grupos guerrilleros. 
sido presionados para votar en favor de alguien (el promedio es $2 \%$ ). Existen además reportes de amigos o parientes que han sido presionados (el promedio es 3,3\%). Sobre estos asuntos altamente sensibles, las preguntas típicamente se formulan sobre el comportamiento del individuo mismo y sobre sus amigos o parientes, ya que la gente normalmente no está dispuesta a reconocer que ha sido directamente amenazada -tal vez por temor a la retaliación- y está un poco más dispuesta a hacerlo cuando se refiere a un tercero. Adicionalmente, la figura $2 \mathrm{~b}$ muestra que existen amenazas a ciudadanos para que se abstengan, pero son menos frecuentes que las presiones para votar por candidatos particulares. Además, ambas figuras revelan que las presiones no son distribuidas de manera homogénea a escala regional. Estas amenazas se sienten más fuertemente en los llamados antiguos Territorios Nacionales, es decir, en los departamentos menos desarrollados y de más difícil acceso del país, que son bastiones de las guerrillas y los ejércitos paramilitares.

\section{2. ¿Las elecciones son transparentes?}

Se deduce de la sección anterior que las elecciones no son particularmente transparentes en Colombia, dado que los ciudadanos y los políticos son amenazados, muchas veces a punta de pistola, para votar en formas diferentes y contrarias a las cuales ellos preferirían. No obstante, se debería mencionar que incluso los reclamos de fraude electoral no han sido tan comunes como se esperaría. Es decir, no hasta el descubrimiento de la complicidad entre los políticos y los grupos paramilitares -el escándalo de la parapolítica. Este término alude a una serie de acuerdos entre los líderes paramilitares y políticos locales para apoyarse mutuamente. Los paramilitares se aseguraban de que el político ganara la elección mediante la intimidación de los candidatos de la oposición y de los votantes. A su turno, los políticos elegidos hacen vista gorda ante las actividades ilegales de los paramilitares (Duncan, 2007; Romero, 2007). Hasta la fecha, 73 miembros del Congreso han sido investigados por las autoridades judiciales por posibles vínculos con grupos armados ilegales, es decir, alrededor del 30\% de todos los miembros de dicha institución.

Se ha argumentado que la expansión paramilitar se correlaciona con el crecimiento de nuevos partidos políticos en las regiones de control paramilitar (Valencia, 2007). A pesar de su novedad, las autoridades judiciales han investigado algunos de estos casos y han condenado a algunos de los actores responsables. Sin embargo, existe ya el antecedente de la colusión entre políticos locales y actores armados al margen de la ley que permite a los primeros ser elegidos en cargos populares con apoyo de los segundos quienes se encargan de coercionar a los ciudadanos. Las autoridades políticas y judiciales del país deben estar alerta frente a este tipo de asociaciones que afectan el desarrollo libre, justo y competitivo de las elecciones.

La complicidad con los paramilitares no ha desplazado formas más tradicionales de clientelismo, como la compra de votos. Las relaciones clientelistas continúan presentes en la política colombiana, como se puede ver en la figura 3 , y suelen ser usadas por grupos 
ilegales para mantener el poder local. Los datos en esta figura son únicos. La encuesta de LAPOP de 2007 incluyó preguntas francas, pero directas, acerca de si los individuos han recibido ofertas de vender su voto. Hasta donde sabemos, es el primer estudio en el que se incluyen estas preguntas en una muestra representativa de colombianos. Aunque la evidencia anecdótica sugería que era una práctica común, no existía evidencia sólida que documentara qué tan extendida era. Sorpresivamente, la figura 3 revela que un promedio de $16 \%$ de todos los individuos recibieron una oferta para vender su voto, es decir, uno de cada seis ciudadanos. En algunas regiones, como la costa Atlántica o los antiguos Territorios Nacionales, la proporción sube hasta uno de cada tres, y parece que los vínculos clientelistas son aún más fuertes allí. Más sorprendente es que las personas denuncian que de sus amigos o parientes que han recibido ofertas para vender sus votos, un promedio de $73 \%$ han aceptado tales ofertas, es decir, casi tres de cada cuatro (los individuos están menos dispuestos de admitir su tendencia de vender votos - ¿es así o se trata de ciudadanos honorables que tienen amigos y parientes muy poco escrupulosos?). Estas respuestas son aún más reveladoras si se tiene en cuenta que la encuesta se cursó en julio de 2007, aproximadamente tres meses antes de las elecciones locales. En otras palabras, dicha consulta se realizó en medio de una campaña electoral.

Figura 3

a) Individuos que recibieron ofertas para vender el voto

(Muestra completa)

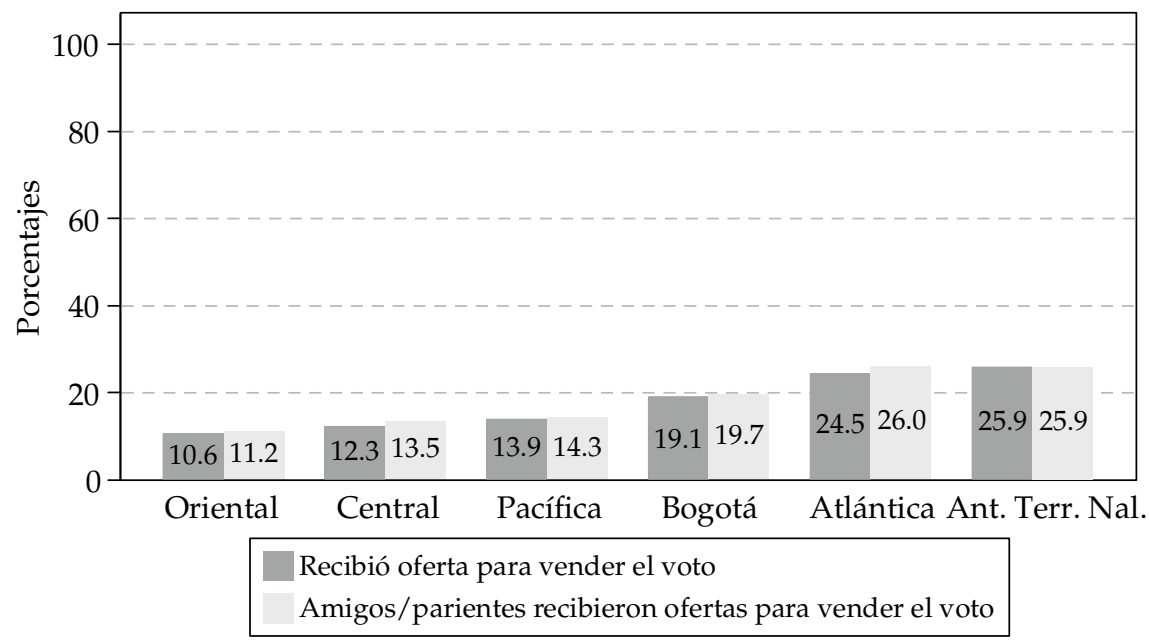

Fuente: LAPOP, Colombia, 2007. 
b) Individuos que admitieron vender el voto (Subconjunto de los que recibieron oferta para vender el voto)

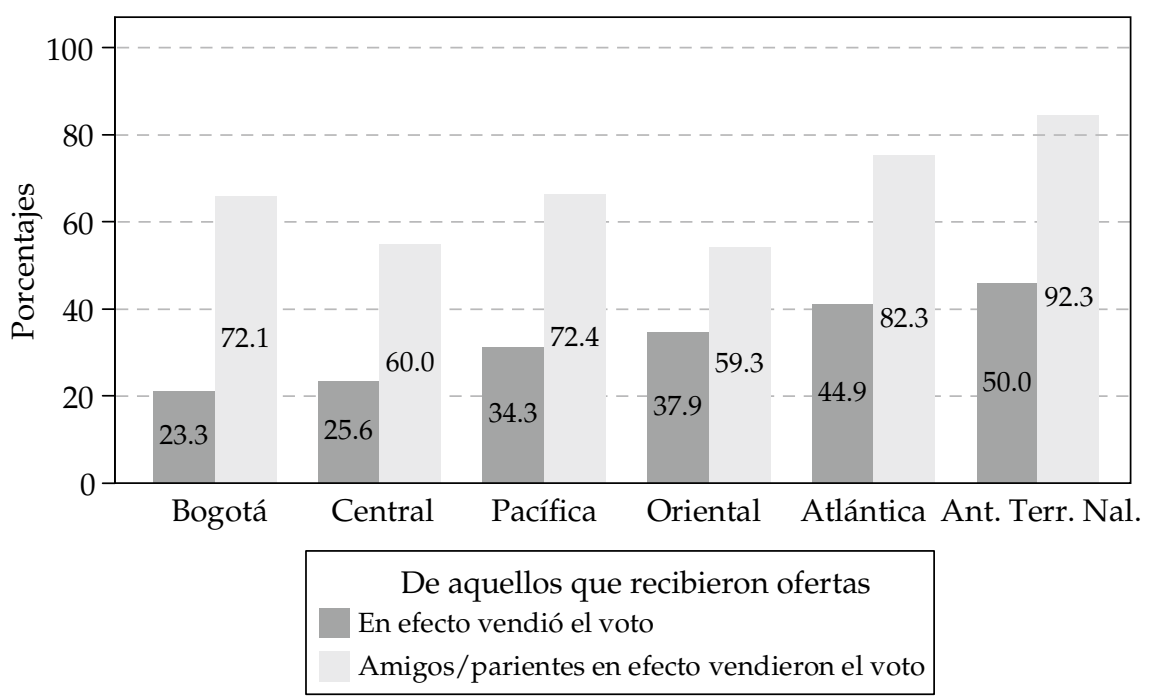

Fuente: LAPOP, Colombia, 2007.

Esta figura muestra los datos sobre la transparencia de las elecciones en Colombia. El panel superior (a) representa el porcentaje de colombianos que afirman haber recibido ofertas para "vender" su voto a cambio de dinero o bienes (datos desglosados por región). Estas cifras son especialmente elevadas en regiones como la costa Atlántica, y los antiguos Territorios Nacionales, donde casi uno de cada cuatro ciudadanos ha recibido dichas ofertas. El panel inferior (b) muestra el porcentaje de los individuos que recibieron ofertas para vender su voto y que admitieron haber aceptado dinero o bienes a cambio del mismo. En promedio, alrededor de un tercio de los encuestados admitió haber vendido su voto, y según afirmaron, cerca de dos tercios de sus familiares o amigos también lo hicieron. Esto proporciona un contraste notorio entre lo que la gente admite sobre su propio comportamiento y el comportamiento de sus parientes cercanos o amigos.

Adicionalmente, el financiamiento de las campañas es otro asunto sensible que tiene implicaciones en la transparencia de las elecciones. Actualmente Colombia tiene un sistema mixto de financiamiento de las campañas con fondos públicos y privados. Las regulaciones laxas y el escaso control del financiamiento privado crea oportunidades para que los actores ilegales puedan intervenir en las elecciones por medio del financiamiento de las campañas. También les permite a los candidatos ocultar las contribuciones -legales e ilegales- que violan las limitaciones de gastos. Los funcionarios electorales estiman que solamente el $30 \%$ de los recursos de cada campaña son reportados en la actualidad (Transparency International, 2007). Es un asunto muy serio que socava la democracia y se convierte en una falta de claridad en el financiamiento de las campañas que permite la interferencia inapropiada de intereses económicos poderosos, legales o no, en un intento por asegurar los beneficios de los funcionarios elegidos. 


\section{3. ¿ Las elecciones son libres?}

La discusión anterior también pone en cuestión qué tan libres son realmente las elecciones en Colombia. Como se mencionó, las guerrillas y los paramilitares interfieren negativamente en el desarrollo libre de las elecciones en Colombia, y los ciudadanos perciben que éste es el caso. La figura 4 presenta la evidencia, de nuevo de LAPOP, mostrando el grado en que los ciudadanos colombianos creen que las elecciones están en peligro. En este caso, la cuestión fue planteada específicamente para preguntar sobre supuestas amenazas a las elecciones locales que se llevaban a cabo en ese momento en particular. Alrededor del $30 \%$ de las personas creían que las elecciones en sus municipios no serían libres ni justas. Además, los encuestados son capaces de identificar el origen de las amenazas a las elecciones en sus pueblos natales. Las personas identifican las amenazas de los traficantes de drogas como menos graves y las del clientelismo como las de mayor repercusión.

Figura 4: Percepción de amenazas en elecciones locales

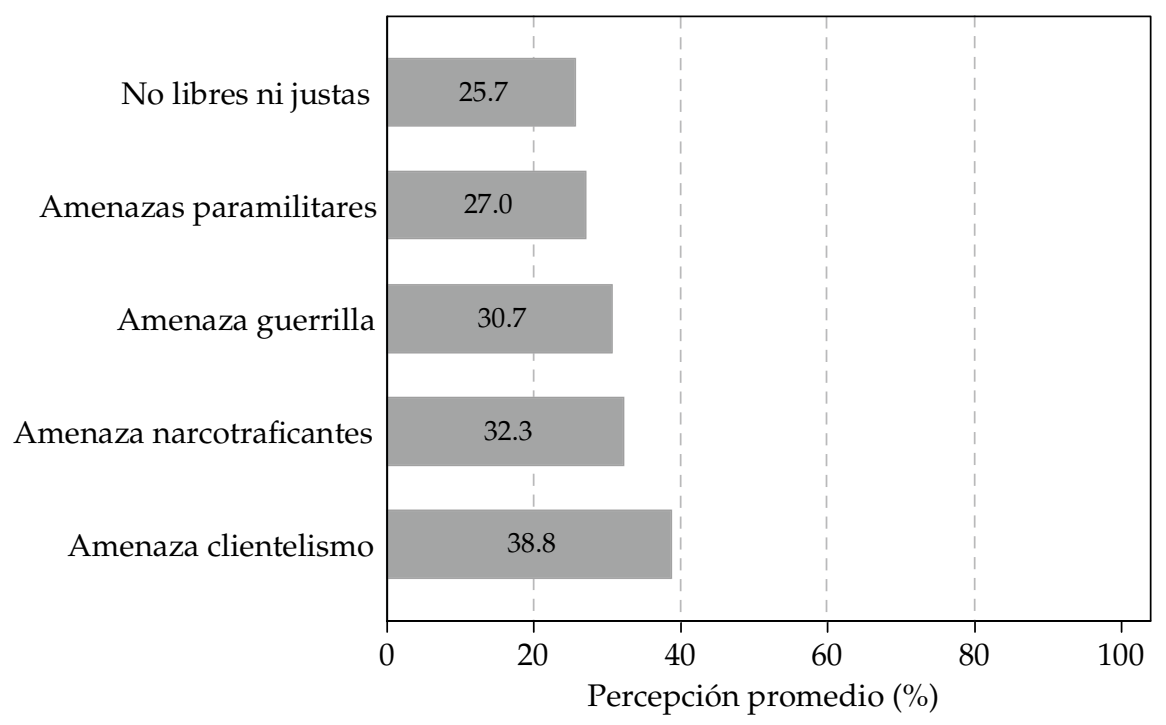

Fuente: LAPOP, Colombia, 2007.

Esta figura muestra la percepción global de la amenaza que los colombianos sintieron durante las elecciones locales de 2007. La figura muestra los diversos tipos de amenazas que provienen de diferentes fuentes. Estas fuentes incluyen las políticas, con las cuales está relacionada la percepción de que las elecciones no son libres o justas y de que las relaciones clientelistas obstaculizan el desempeño democrático. También se incluyen las amenazas que proceden de grupos ilegales como la guerrilla, los paramilitares y los narcotraficantes. 
Aparte de lo que hemos dicho en términos de las amenazas documentadas a las elecciones por los actores ilegales, como la guerrilla y los paramilitares, estos datos revelan que en realidad los ciudadanos perciben que las elecciones son asediadas por múltiples actores. Así, para un número considerable de colombianos las elecciones son eventos en que una de las libertades fundamentales de la población es obstaculizada.

\section{RELACIONES ENTRE LOS PODERES EJECUTIVO Y LEGISLATIVO, Y EL RESULTANTE EQUILIBRIO DE PODER}

Se ha argumentado desde hace tiempo que la mera separación de poderes, entendida como la existencia de las cadenas de la competencia de la delegación con los términos fijos y de supervivencia independiente, no es suficiente para garantizar una representación adecuada de los intereses de los ciudadanos. Es necesario que los poderes Ejecutivo y Legislativo tengan por igual la capacidad de veto de unos a otros cuando surja un desacuerdo.

Adicionalmente, se ha establecido un amplio consenso compartido tanto por legisladores como por académicos para que los controles reales y los balances funcionen, el diseño constitucional no es suficiente. Una democracia saludable requiere la presencia de los partidos políticos. Éstos originan las preferencias en los individuos que buscan la reelección y sirven como un atajo para que los ciudadanos se informen y aprovechen al máximo sus preferencias y, lo más importante, ayuden para que la rendición de cuentas sea posible (Powell, 2000; Shugart y Carey, 1992; Haggard y McCubbins, 2001).

Por lo tanto, en esta sección haremos una descripción del sistema de partidos políticos para describir los desarrollos más recientes durante las dos administraciones de Uribe. También describiremos las instituciones que regulan las relaciones entre el poder Ejecutivo y el Legislativo, y su situación actual. Por último, evaluaremos una fuente adicional de amenaza para la democracia colombiana: la concentración de poder en manos del Ejecutivo y los problemas asociados con las relaciones entre las distintas ramas del poder.

\section{a. El sistema de partidos políticos}

El sistema colombiano de partidos data de los primeros años de la República, y era considerado uno de los más antiguos y más institucionalizados de América Latina (Mainwaring y Scully, 1995). Dos partidos -el Liberal y el Conservador-dominaron la arena electoral colombiana durante la mayor parte de la vida republicana. Hasta hace poco, la década de 1990, las etiquetas de los partidos y la identificación partidista jugaron un papel dominante en muchos aspectos de la vida política (Pinzón de Lewin, 1989). La reforma de descentralización de 1986 y la reforma constitucional de 1991 resultaron en una disminución del umbral para la formación de partidos políticos, dejando a los directorios de los partidos existentes sin mucho control sobre sus miembros en la arena electoral. Anteriormente, los directorios de los partidos estaban muy fraccionados, pero los poderes de nombramiento del Presidente permitían tanto a liberales como a conservadores 
tener el control sobre las modalidades de la carrera de sus políticos. Crecientemente, la fragmentación del sistema de partidos se convirtió en una característica evidente del sistema de partidos. Aunque las etiquetas de los partidos todavía se utilizaban, en parte porque la presidencia estaba en manos de uno de los partidos tradicionales, los problemas de coordinación dentro de los partidos Liberal y Conservador eran difíciles de superar (Gutiérrez, 2002; Pachón, 2002). La competencia interna y entre partidos se tornó crítica a partir de 1998, cuando el Partido Liberal perdió las elecciones presidenciales (Pizarro, 2002; Rodríguez-Raga, 2002; Shugart et al., 2006).

Después de varios intentos fallidos para reformar el sistema electoral, una reforma constitucional aprobada en 2003 asignó a las organizaciones partidarias un papel crítico en el sistema político. El cambio en el sistema electoral de cuota simple y mayores residuos -sin restricción en el número de listas por partido- a un sistema de divisores de D'Hondt, con opción de listas abiertas (voto preferente), significó una partida importante de los altos niveles de competencia entre partidos y dentro de ellos. De 72 partidos legalmente reconocidos y 42 con representación en el Congreso en 2002, como resultado de la elección de 2006 el número de partidos políticos reconocidos legalmente se redujo a 22 y sólo 10 de ellos obtuvieron representación en el Congreso.

Aunque el uso de listas abiertas aún permite la competencia dentro de los partidos, la restricción de presentar una lista por partido, la existencia de puesta en común de la votación y las de magnitudes de distrito relativamente bajas generan nuevos incentivos para imponer la disciplina y auspiciar coaliciones preelectorales (Botero y RodríguezRaga, 2006; Pachón y Shugart, 2009).

Otras reformas responsables del reajuste del sistema de partidos son las reformas constitucionales que permiten la reelección inmediata del presidente y la Ley de Bancadas, que regula el comportamiento de los partidos políticos en el Congreso y otros cuerpos colegiados a nivel subnacional (Ungar, 2008), ambas aprobadas en el primer período presidencial de Álvaro Uribe Vélez. Su promulgación devolvió a los líderes de los partidos la posibilidad de sancionar y premiar a sus miembros con una probabilidad mayor que las negociaciones programáticas con la rama ejecutiva. Por ejemplo, sólo los líderes del partido pueden convocar audiencias y tienen derechos preferentes en los debates plenarios, así como designar el orador de los proyectos de ley de autoría del partido (anteriormente realizada por el comité de dirección) o solicitar votos nominales. Además, el partido o las bancadas de la coalición están obligados a votar como una unidad -con la excepción de los casos en que las partes consideren "votos de conciencia". Este tipo de voto es usual en los sistemas parlamentarios, y se limita a los casos en que el partido no tiene una línea política clara, o involucran cuestiones éticas o morales. Puesto que las sanciones están reguladas por los estatutos de cada partido, y bien puede ser que no sean de aplicación general, esta excepción ha sido muy criticada, ya que crea un vacío legal que permite la indisciplina de los partidos.

Sin duda, el papel del presidente Uribe y sus extraordinarios niveles de popularidad permiten entender las circunstancias por las cuales las numerosas reformas han sido aprobadas, y las coaliciones de procedimiento formadas en el Congreso. Esto se puede 
observar en las elecciones parlamentarias de 2006, donde el modelo de coaliciones preelectorales identificadas y los partidos nuevos tuvieron una clara referencia al presidente Uribe. Por ejemplo, el Partido de la U está formado por antiguos dirigentes del Partido Liberal y otros congresistas que han apoyado la enmienda constitucional que garantiza la reelección de Uribe y respalda sus principales propuestas políticas. Su comportamiento en el Congreso ha demostrado que a pesar de estar al lado del gobierno, siguen siendo una coalición frágil, de intereses muy heterogéneos. ${ }^{4}$

Otro desafío crucial para la coalición de gobierno ha sido la continua renuencia del Presidente a comprometerse con cualquier etiqueta política, lanzándose como independiente tanto en las elecciones de 2002 y de 2006. De esta manera ha disminuido los incentivos para que las organizaciones partidarias que lo apoyan puedan convertirse en una coalición política coherente, una vez en el gobierno. La falta de una organización y de una delegación mínima de poderes del Presidente a su equipo hace que estos políticos en gran medida dependan de la imagen y el rendimiento del Presidente. La propuesta de una reelección consecutiva, que se está debatiendo actualmente, es, en parte, consecuencia de esto. ¿Qué líder diferente del presidente Uribe puede mantener unidos estos partidos recién formados?

Sin embargo, en comparación con elecciones anteriores, en las cuales los votantes fueron principalmente identificados con los candidatos (ya que es difícil usar el partido como un atajo a la información), el nuevo sistema electoral facilita a los votantes identificar las propuestas políticas. La estabilidad del sistema de partidos en las elecciones futuras es un factor determinante para que las nuevas reformas se traduzcan en un esfuerzo de mayor acción colectiva en nombre de los candidatos, y para mejorar la responsabilidad vertical.

El éxito de los partidos de la oposición en las elecciones locales -como las de Bogotá, donde el Polo Democrático ganó dos comicios consecutivos- se puede considerar como otro resultado exitoso resultante de los cambios institucionales en el sistema electoral. No sólo los partidos tradicionales se adaptaron a los cambios institucionales, sino que las fuerzas que anteriormente eran independientes se han organizado colectivamente, formando partidos políticos nuevos que han tenido éxito relativo.

\section{b. Las relaciones entre Ejecutivo y Legislativo}

Como otros países de la región, Colombia se caracteriza por el presidencialismo fuerte, dados los poderes proactivos del Presidente que le permiten introducir legislación y cambiar unilateralmente el statu quo durante "tiempos excepcionales" (Archer y Shugart, 1997). Aunque la Constitución de 1991 forzosamente limita los poderes unilaterales del

4 Miembros bastante reconocidos del partido han renunciado a sus puestos o han declarado públicamente ser “disidentes" de la organización central del partido. Véase, por ejemplo, http:/ /www.elpais.com.co/paisonline/ notas/Diciembre142008/nal2.html 
presidente, el papel del Ejecutivo como el regulador de la agenda principal continúa. ${ }^{5}$ Esto es consecuencia de sus prerrogativas constitucionales en la mayoría de las áreas de la política. El Presidente cuenta con varios instrumentos que le permiten controlar la agenda legislativa. Entre otros, el Ejecutivo tiene poder de veto procedimental y sustantivo, puede declarar el estado de sitio, puede pedir marcar como urgente un proyecto de ley para darle prioridad en la agenda legislativa y tiene áreas de política reservadas en la que la introducción de proyectos de ley es su potestad exclusiva.

Aunque en comparación con el Ejecutivo, el Congreso no parece promulgar tanta legislación, todavía juega un papel importante. La tabla 1 muestra el porcentaje de proyectos de ley iniciados por cada rama del gobierno. En promedio, el Congreso presenta el $80 \%$ de los proyectos de ley. Después de 1991, el 60\% de los proyectos de ley presentados son de "alcance nacional", mientras que el resto son de alcance más regional, local o individual en su ámbito de aplicación. Se espera que los legisladores presenten proyectos de ley dirigidos a proveer bienes públicos a sus electores. $\mathrm{Al}$ comparar las tasas de éxito, el Congreso se queda corto en comparación con el Ejecutivo. La tasa de éxito del Congreso se acerca al 10\%. ${ }^{6} \mathrm{El}$ Congreso históricamente se ha especializado en los proyectos de ley dirigidos a grupos locales o regionales. Sin embargo, esto no implica la abdicación del Congreso en los asuntos nacionales. Debido al hecho de que el Presidente está obligado a tramitar por el escenario del Congreso para promulgar su legislación, los congresistas son proactivos en términos de la introducción de enmiendas en proyectos de ley de autoría del Ejecutivo. Cárdenas et al. (2008) muestran cómo el número de "padrinos" de un proyecto de ley es un importante predictor de éxito. Sin embargo, en comparación con otros países de la región como Brasil $(72 \%)$ o Chile $(80 \%)$, el control de la agenda del Congreso en plenaria por parte del Ejecutivo en Colombia es relativamente bajo, con un promedio de 50\% después de 1991 (Carroll y Pachón, 2008).

La membresía exclusiva de las comisiones contrasta con otras legislaturas de América Latina, donde los miembros pertenecen a varias comisiones y, por tanto, no tienen incentivos para especializarse. ${ }^{7}$ El Congreso de Colombia tiene sólo siete comisiones permanentes establecidas en la Constitución, frente a las legislaturas de México o Argentina, que tienen más de 35 comisiones permanentes con jurisdicciones que se sobreponen. Este hecho

5 La Constitución de 1991 restringió altamente el poder de decreto presidencial mediante la limitación de las áreas de política y el marco de tiempo en que el Ejecutivo podría utilizar estos poderes. Adicionalmente, la creación de la Corte Constitucional añadió un actor de veto adicional a la declaración de los estados de excepción, lo que hace difícil para el Ejecutivo manipular y abusar de los poderes excepcionales.

6 Esta cifra se calcula considerando el número de los proyectos de ley que fueron promulgados y el número total de proyectos de ley presentados al Congreso. En este cálculo no excluimos del denominador los proyectos de ley que aún están en proceso. Así, la cuantía es relativamente baja en comparación con otros casos que aparecen en la literatura, en los cuales el denominador es solamente calculado a partir de los proyectos de ley que han pasado por el proceso completo.

7 Cada cámara está organizada en siete comisiones que tienen un papel importante en el funcionamiento del Congreso. Los comités relacionados con la Constitución y cuestiones económico-presupuestarias se encuentran entre los más apetecidos por los políticos. La membresía del partido es indispensable para alcanzar un puesto en el comité preferido. Esto es importante porque muestra que incluso con la fragmentación de los partidos y una competencia entre partidos pronunciada, las estructuras de éstos juegan un papel en la organización de la actividad legislativa. 
Tabla 1: Iniciación de proyectos de ley por la Administración, 1982-2002

\begin{tabular}{|c|c|c|c|c|c|c|c|c|c|}
\hline \multirow{2}{*}{ Administración } & \multirow{2}{*}{$\begin{array}{l}\text { Fecha de } \\
\text { posesión }\end{array}$} & \multirow{2}{*}{$\begin{array}{l}\mathrm{N}^{\circ} \mathrm{de} \\
\text { años* }\end{array}$} & \multicolumn{3}{|c|}{ Autor } & \multirow{2}{*}{ Total } & \multicolumn{3}{|c|}{ Autor $(\%)$} \\
\hline & & & Legislativo & Ejecutivo & Otro & & Legislativo & Ejecutivo & Otro \\
\hline Belisario Betancur & $08 / 07 / 82$ & 2 & 262 & 98 & 3 & 363 & 72 & 27 & 1 \\
\hline Virgilio Barco & $08 / 07 / 86$ & 2 & 305 & 39 & 7 & 351 & 86 & 11 & 2 \\
\hline César Gaviria & $08 / 07 / 90$ & 1 & 286 & 72 & 12 & 370 & 77 & 19 & 3 \\
\hline Ernesto Samper & $08 / 07 / 94$ & 4 & 905 & 231 & 22 & 1.158 & 78 & 20 & 2 \\
\hline Andrés Pastrana & $08 / 07 / 98$ & 4 & 749 & 142 & 29 & 920 & 81 & 15 & 3 \\
\hline Álvaro Uribe & $08 / 07 / 02$ & 1 & 211 & 49 & 1 & 261 & 81 & 19 & 0 \\
\hline Total & & & 2.72 & 631 & 74 & $3.423^{* *}$ & 79 & 18 & 2 \\
\hline
\end{tabular}

* Años cubiertos en la base de datos (de un total de 4).

** El número total de proyectos de ley es 3.428 . El cuadro presenta 3.423 proyectos de ley porque 5 no están clasificados por autor.

Nota: la base de datos no incluye todas las leyes presentadas en cada administración.

Fuente: Cárdenas et al., 2008.

aumenta el poder político del Congreso ya que las comisiones son un paso obligado para la introducción de la legislación. El Ejecutivo puede decidir si desea presentar proyectos de ley tanto en la Cámara de Representantes o del Senado, y si introduce el proyecto de ley o enmienda constitucional en las comisiones conjuntas del Congreso. La pertenencia a las comisiones económicas y de presupuesto es altamente valorada, debido a la proximidad a los fondos del gobierno. La comisión encargada de los asuntos constitucionales y políticos también es muy visible, y la afiliación es muy reñida. Los índices de pertenencia de puestos a estas tres comisiones son significativamente más altos con un $50 \%$ en promedio, en comparación con la tasa de ocupación promedio de la Cámara que son del 37\% aproximadamente (Cárdenas, et al., 2008).

Como consecuencia de la profesionalización creciente, los índices de pertenencia a las diferentes comisiones han aumentado de manera constante desde la década de 1930. De un $10 \%$, que era el índice de participación de puestos en 1935, la tasa ha aumentado un $50 \%$ para el Senado y un 38\% para la Cámara durante los últimos 10 años. No obstante, y posiblemente como resultado de una mayor fragmentación, los índices de pertenencia a las comisiones han disminuido tanto en la Cámara como en el Senado después de la promulgación de la Constitución de 1991. Sin embargo, en comparación con los índices de participación de otros países latinoamericanos, Colombia tiene una de las más altas tasas de reelección. Por ejemplo, en Argentina la tasa de reelección es 17\% y en Brasil es 45\%. Ciertamente, hay miembros del Congreso que tienen una carrera larga y se consideran "legisladores profesionales". Sin embargo, la figura de "legisladores principiantes" no es ajena al Congreso de Colombia.

Así pues, podemos concluir que el Congreso siempre ha sido un actor importante de veto para el Presidente. Los legisladores han sido autores de trascendentales enmiendas 
constitucionales, tales como la Ley de Bancadas y la de Reforma Electoral de 2003. No obstante, para que el Congreso cumpla eficazmente sus tareas legislativas es necesario desarrollar una mejorada capacidad de investigación centralizada, los partidos deben demostrar más cohesión y establecer más coaliciones y, sobre todo, más apalancamiento en la explotación de su propia agenda. Los poderes procedimentales del presidente, como la petición de urgencia y la introducción de iniciativa exclusiva de la legislación, son suficientes para controlar la agenda del Congreso. Las reformas llevadas a cabo durante el período actual han generado algunos necesarios (aunque no suficientes) incentivos para que los partidos se orienten nacionalmente y tengan más contenido programático. No obstante, dado que el sistema electoral seguirá patrocinando el componente "basado en el candidato", se espera también que los tratos no programáticos garanticen la supervivencia de los partidos políticos. Aunque el gobierno ha tratado de eludir el apoyo del Congreso, como ocurrió con el referéndum de 2003, los instrumentos de democracia directa son muy difíciles de usar a escala nacional y significan un alto costo político. Luego, el presidente necesita negociar. A diferencia de cómo sería interpretada en otros países de la región, ésta es una buena noticia para el equilibrio de poder deseado en una democracia presidencial.

\section{c. El balance de poder: Uribe vs. la Constitución}

El equilibrio de poder entre las ramas del gobierno ha sido alterado como resultado de la reelección del presidente Uribe. En 1991, los reformadores constitucionales conscientemente prohibieron la reelección, inmediata o no, del jefe del Ejecutivo, y en vista de ello las relaciones entre las ramas fueron diseñadas bajo la premisa de que el jefe del Ejecutivo ocupara su cargo por un máximo de cuatro años (Botero y Vélez, 2008; Ungar, 2008). Cuando el Congreso aprobó la reforma constitucional que permitió al presidente Uribe buscar un segundo mandato, sólo se eliminó la prohibición a los presidentes de buscar la reelección y no se cambiaron los principales aspectos institucionales que garantizan los controles y equilibrios efectivos. A saber, el Presidente tiene grandes poderes de nombramiento y nominación que le permiten nominar a candidatos afines a puestos clave en los distintos organismos gubernamentales, como las oficinas de control (procurador general, contralor, defensor del pueblo), o en los organismos de planificación económica (Banco de la República, Departamento de Planeación Nacional). Además, la concentración de poder en manos del Presidente le ha permitido desafiar a las instituciones que cuestionan su administración, tal como se manifiesta en las réplicas pugilísticas dirigidas a la Corte Suprema de Justicia (CSJ). Estos dos asuntos -los poderes de nominación y el conflicto con la CSJ- se desarrollan en esta sección.

La independencia institucional establecida por la Constitución de 1991 se basó en el principio de que el Presidente designa y nombra los funcionarios que servirán en la mayoría de las instituciones durante el período siguiente al suyo. La idea era reducir la capacidad de los presidentes para designar y nombrar personas afines al Ejecutivo para que ejercieran en los puestos de control clave durante su propia administración. La reforma constitucional que permitió la reelección presidencial no hizo ajustes a los procedimientos de nombramiento ni a los términos de dichos puestos clave, como 
los jueces en los tribunales superiores, los jefes de los organismos de supervisión, los miembros de la junta directiva del Banco de la República, etc.

Una de las instituciones en las cuales el gobierno ha adquirido una mayor capacidad de interferencia es el Consejo Superior de la Judicatura, que se encarga de garantizar la autonomía de la rama judicial. Este tribunal está compuesto por dos cámaras, a saber, la Sala Administrativa y la Sala Disciplinaria. Los magistrados de esta última, encargados de estudiar los casos relacionados con las faltas disciplinarias de los miembros de la judicatura y de los abogados en general, son nombrados por el Congreso entre los candidatos propuestos por el Presidente y tres candidatos por cada puesto disponible. Para 2008, todos los magistrados en esta Cámara habían sido nombrados por el presidente Uribe.

El gobierno también ha adquirido influencia sobre el Banco de la República al nombrar al gerente general y a los miembros de la Junta Directiva. Durante su primera administración (2002-2006), el presidente Uribe nombró a cuatro de los siete miembros de la Junta Directiva; en 2008 tuvo la oportunidad de nombrar dos miembros adicionales, con lo cual terminó designando un total de seis de los siete miembros. La Constitución de 1991 había ideado un sistema de designación que permitía que el presidente de turno nombrara a un máximo de dos miembros de dicha Junta. Este esquema protegía la independencia del Banco de la República para que las políticas macroeconómicas y fiscales se mantuvieran lejos de los ciclos políticos. Esa independencia hoy está rota.

Además, el presidente Uribe también nominó dentro de una terna al actual fiscal general (Fiscalía), quien sirvió como viceministro de Justicia durante la primera administración del presidente Uribe antes de ser nombrado para su cargo actual.

Los desequilibrios institucionales que resultan de una reforma desordenada se verán agravados por un tercer mandato consecutivo. Aunque el presidente Uribe aún no ha declarado oficialmente su intención de buscar otra reelección, es muy probable que lo haga. Colaboradores cercanos a él han recogido más de 5 millones de firmas de ciudadanos que apoyan un referéndum para cambiar la Constitución, una vez más, para que pueda buscar un tercer mandato. Su intención también se ha hecho evidente al emitir un decreto presidencial minutos antes de que finalizara la sesión legislativa que convocaba al Congreso a reunirse en sesiones extraordinarias para discutir el proyecto de ley que permite el referéndum para su reelección (El Tiempo, 2008).

Además, el mismo presidente Uribe ha demostrado poco respeto por el principio del sistema de controles y equilibrios, como bien lo demuestran sus altercados con la Corte Suprema sobre las investigaciones de complicidad entre los políticos y paramilitares. Igualmente preocupantes son sus comentarios despectivos hacia los miembros de la oposición o de quien no está de acuerdo con él. ${ }^{8}$

8 Por ejemplo, en respuesta a las denuncias del senador de la oposición, y actual candidato a la presidencia por el Polo Democrático Alternativo, Gustavo Petro, según las cuales el hermano del presidente tenía vínculos con grupos paramilitares, el jefe de Estado llamó al senador Petro "terrorista de corbata" (El Tiempo, 2007a y 2007b). De igual manera, para desacreditar los esfuerzos de Colombianos por la Paz, un grupo de civiles dirigido por la senadora de oposición Piedad Córdoba, que hizo posible la liberación de cuatro miembros 


\section{CONCLUSIONES: LAS INSTITUCIONES NO SON TODO}

En este artículo hemos ofrecido nuestra evaluación del estado de la democracia actual en Colombia. Hemos recalcado que existe una fuerte tensión entre la forma y la sustancia en el desempeño democrático del país. A diferencia de la mayoría de los países de la región, Colombia ha vivido bajo la institucionalidad democrática de forma continua las últimas décadas. Esta experiencia, sin lugar a dudas, tiene consecuencias positivas. La principal de ellas tiene que ver con el hecho de que las instituciones formales existan y sean respetadas. Sin embargo, la lección clave que se puede extraer de Colombia para otras democracias de la región es que la existencia de instituciones formales no garantiza que los resultados obtenidos sean los deseados. La celebración regular de elecciones genera buenos hábitos en los ciudadanos, pero no neutraliza de forma automática los riesgos que pueden enfrentar los gobiernos democráticos. En el caso particular de Colombia, estos riesgos provienen de amenazas externas y también del interior mismo de la democracia; de la interacción entre los actores relevantes.

Es cierto que consideramos que la principal amenaza que pesa sobre la democracia colombiana está relacionada con factores extrainstitucionales y de forma específica con la situación de conflicto armado interno. El conflicto colombiano no sólo es de carácter político, sino que también tiene una dimensión puramente criminal. A riesgo de simplificar, ambos bandos del conflicto, guerrillas y paramilitares, se han beneficiado del narcotráfico como mecanismo de financiación de la guerra. Así, en años recientes han abundado los actores armados ilegales con motivaciones diferentes pero con interés en controlar territorios y poblaciones para poder desarrollar su guerra. La consecuencia nefasta para la democracia han sido las alianzas entre estos actores y algunos sectores de la clase política. Ese es el origen de la principal amenaza a la democracia: el incrustamiento de las mafias en el poder político.

Ahora, si bien el conflicto que vive el país es particular a Colombia, hay ciertos elementos que trascienden su particularidad y pueden ser lecciones para otros países. El problema del narcotráfico tiene claros alcances globales y de la misma forma que las mafias colombianas han penetrado el Estado colombiano para proteger sus intereses, pueden hacerlo en aquellos países en los que exista alguno de los eslabones de la cadena de producción de drogas ilegales (desde cultivos hasta lavado de activos).

Asimismo, la democracia colombiana sufre de amenazas internas. La reforma a la Constitución que permitió la reelección del presidente Uribe se hizo sin tener en consideración los efectos que podía tener sobre el equilibrio institucional existente. En su momento, el debate se planteó en términos de extender el mandato de un presidente popular y el argumento es similar ahora que se debate una segunda reelección. Se trata de un argumento válido pero cuestionable. Sin embargo, el debate no ha incluido una discusión profunda sobre cómo alterar otras instituciones para que controlen el poder

del ejército y de dos civiles secuestrados por las FARC, el presidente Uribe tácitamente se ha referido a ellos como el "bloque intelectual" de las FARC y ha afirmado que su objetivo es desorientar a la opinión pública (El Tiempo, 2009). 
del Ejecutivo, ni cómo proteger los derechos de la oposición de manera que tengan condiciones equitativas de competencia con el presidente, que tiene los recursos del Estado a su disposición. Otros países de la región tampoco han sido ajenos a este caudillismo reciente, por lo que su desempeño democrático se ve igualmente comprometido.

Puede que los colombianos hayan aceptado las contradicciones que hemos señalado en este artículo (v.g. elecciones frecuentes y asesinato de sindicalistas), apoyados en el hecho de que las instituciones formales se mantengan. Pero la lección para el país y para otros países en la región es que hay serias amenazas a la sustancia misma de la democracia, que es lo que verdaderamente importa. Es imperativo no hacer caso omiso de estas amenazas.

\section{REFERENCIAS}

Archer, Ronald P. y Matthew S. Shugart, 1997. "The Unrealized Potential of Presidential Dominance in Colombia", en Scott Mainwaring and Matthew S. Shugart (eds.), Presidentialism and Democracy in Latin America, Nueva York, Cambridge University Press.

Arjona, Ana María, 2008. "Grupos armados, comunidades y órdenes locales: un enfoque interrelacional”, en Fernán González (ed.), Hacia la reconstrucción del país: desarrollo, política y territorio en regiones afectadas por el conflicto armado, Bogotá, CINEP-ODECOFI.

Botero, Felipe y Cristina Vélez, 2008. “¿Reelegir o no reelegir? Reformas del sistema de elección presidencial en Colombia", trabajo presentado en la IV Conferencia de la Asociación Latinoamericana de Ciencia Política, 5-7 de agosto, Universidad de Costa Rica.

Cárdenas Mauricio, Roberto Junguito y Mónica Pachón, 2008. "Political Institutions and Policy Outcomes in Colombia: The Effects of the 1991 Constitution", en Policymaking in Latin America: How Politics Shapes Policies, Cambridge, Harvard University Press y Banco Interamericano de Desarrollo.

Carroll, Royce y Mónica Pachón, 2008. "Government Agendas in Presidential Democracies", trabajo presentado en la Reunión de la Asociación Americana de Ciencia Política, Boston.

Duncan, Gustavo, 2007. Los señores de la guerra, Bogotá, Planeta.

El Tiempo, 2008. "En sesiones extraordinarias, Cámara aprobó referendo que permite reelección de Uribe", en http://www.eltiempo.com/archivo/documento/CMS-4727517, consultado el 16 de febrero de 2009.

El Tiempo, 2009. "Piden a Uribe señalar a los del 'bloque intelectual' de las FARC", en http:/ /www. eltiempo.com/archivo/documento/MAM-3308773, consultado el 16 de febrero de 2009.

Fonseca, Ángela, 2008. "El elefante en la Caja Agraria", tesis de grado, Universidad de los Andes, Facultad de Economía.

García Sánchez, Miguel, 2006. “On Bullets and Ballots: Political Violence and Electoral Turnout in Colombia, 1990-1994", Universidad de Pittsburgh, inédito.

Gutiérrez, Francisco (ed.), 2002. Degradación o cambio: evolución del sistema político colombiano. Bogotá: Norma.

Haggard, Stephan y Matthew D. McCubbins, 2001. Presidents, Parliaments and Policy, Nueva York, Cambridge University Press.

International Trade Union Member Confederation, 2007. "Annual Survey of Violations of Trade Union Rights 2007", en http:/ / survey07.ituc-csi.org/, consultado el 5 de diciembre de 2008.

International Trade Union Member Confederation, 2008. "Annual Survey of Violations of Trade Union Rights 2008". En línea http://survey08.ituc-csi.org/, consultado el 5 de diciembre de 2008.

Leal Buitrago, Francisco y Andrés Dávila, 1990. Clientelismo: el sistema politico y su expresión regional, Bogotá, Tercer Mundo, IEPRI. 
Losada, Rodrigo, 2001. "Violencia y elecciones en Colombia: año 2000", en Fernando Giraldo, Rodrigo Losada y Patricia Muñoz (eds.), Colombia: elecciones 2000, Bogotá, Ceja.

Mainwaring, Scott y Timothy Scully, 1995. Building Democratic Institutions: Party Systems in Latin America, Stanford, Stanford University Press.

Norris, Pippa (ed.), 1999. Critical Citizens. Global Support for Democratic Governance. Oxford: Oxford University Press.

Pachón, Mónica, 2002. “El Partido Conservador y sus dinámicas políticas", en Francisco Gutiérrez (ed.), Degradación o cambio: evolución del sistema político colombiano, Bogotá, Norma.

Pachón, Mónica y Matthew S. Shugart, 2009. "Party System Rationalization and the Mirror Image of Interparty and Intraparty Competition: The Adoption of Party Lists in Colombia", en http:// mpachon.googlepages.com/workingpapers2

Pinzón de Lewin, Patricia, 1989. Pueblos, regiones y partidos: la regionalización electoral. Atlas electoral colombiano, Bogotá, Ediciones Uniandes.

Pizarro, Eduardo, 2002. "La atomización partidista en Colombia: el fenómeno de las microempresas electorales", en Francisco Gutiérrez (ed.), Degradación o cambio: evolución del sistema político colombiano, Bogotá, Norma.

Programa de las Naciones Unidas para el Desarrollo (PNUD), 2004. Democracy in Latin America: Toward a Citizen's Democracy, Buenos Aires, Alfaguara.

Powell, G. Bingham, 2000. Elections as Instruments of Democracy: Majoritarian and Proportional Visions, New Haven, Yale University Press.

Rodríguez-Raga, Juan Carlos, 2002. “¿Cambiar todo para que nada cambie? Representación, sistema electoral y sistema de partido en Colombia: capacidad de adaptación de las elites políticas a cambios en el entorno institucional", en Francisco Gutiérrez (ed.), Degradación o cambio: evolución del sistema político colombiano, Bogotá, Norma.

Romero, Mauricio, 2007. Parapolítica. La ruta de la expansión paramilitar y los acuerdos políticos. Bogotá: Intermedio y Corporación Nuevo Arco Iris.

Samuels, David y Richard Snyder, 2001. "The Value of a Vote: Malapportionment in Comparative Perspective", en British Journal of Political Science, 31 (4), pp. 651-671.

Shugart, Matthew y John Carey, 1992. Presidents and Assemblies, Nueva York: Cambridge University Press.

Shugart, Matthew, Erika Moreno y Luis E. Fajardo, 2006. “Deepening Democracy by Renovating Political Practices: The Struggle for Electoral Reform in Colombia", en Peace, Democracy, and Human Rights in Colombia, Notre Dame, University of Notre Dame.

The Economist, 2008. “The Economist Intelligence Unit's Index of Democracy 2008”, en http:/ /a330.g.akamai. net/7/330/25828/20081021195552/graphics.eiu.com/PDF/Democracy\%20Index\%202008.pdf

Transparency International, 2007. Proyecto Crinis, "Dinero en la política: asunto de todos", The Carter Center.

Ungar, Elisabeth, 2008. “Equilibrio de poderes: ¿realidad o ficción?", en Razón Pública, 7 de septiembre, en http:/ / www.razonpublica.org.co/?p=159, consultado el 10 de septiembre de 2008.

Ungar, Elisabeth et al., 2008. Las bancadas en el Congreso: ley y praxis, Bogotá, Universidad de los Andes, Escuela de Gobierno Alberto Lleras Camargo.

Valencia, León, 2007. “Los caminos de la alianza entre paramilitares y los políticos”, en Parapolítica: la ruta de la expansión paramilitar y los acuerdos políticos, Bogota, Intermedio Editores.

Velásquez, Fabio, 2008. “Territorio, conflicto y gestión pública en Colombia: una mirada desde lo local”, en Foro Debates, $\mathrm{N}^{\circ} 7$. 
Felipe Botero Ph. D. en Ciencia Política, Profesor Asociado del Departamento de Ciencia Política de la Universidad de los Andes, Bogotá. Sus publicaciones recientes incluyen varios artículos y capítulos sobre el sistema electoral y de partidos en Colombia. Es compilador del libro ¿Juntos pero no revueltos? Partidos, candidatos y campañas en las elecciones legislativas de 2006 en Colombia.

Correo postal: Cra 1E 18A-10, Of. G-319, Bogotá, Colombia.

Tel: +571-339-4949x2615 / Fax: +571-339-4949x3202 / E-mail: fbotero@uniandes.edu.co

Gary W. Hoskin Ph. D. en Ciencia Política, Profesor Titular del Departamento de Ciencia Política de la Universidad de los Andes, Bogotá. Ha publicado ampliamente sobre elecciones, partidos y legislativos en América Latina.

Correo postal: Cra 1E 18A-10, Of. G-319, Bogotá, Colombia.

Tel: +571-339-4949x2616 / Fax: +571-339-4949x3202 / E-mail: ghoskin@uniandes.edu.co

Mónica Pachón Ph. D. en Ciencia Política, Profesora Asistente del Departamento de Ciencia Política de la Universidad de los Andes, Bogotá. Su investigación se centra principalmente en las relaciones Ejecutivo-Legislativo en regímenes presidenciales. Sus trabajos han sido publicados en Revista de Ciencia Política, Política y Gobierno y Legislative Studies Quarterly.

Correo postal: Cra 1E 18A-10, Of. G-319, Bogotá, Colombia.

Tel: +571-339-4949x2609 / Fax: +571-339-4949x3202 / E-Mail: mopachon@uniandes.edu.co 